\title{
Hydrothermal system of the active crater of Aso volcano (Japan) inferred from a three-dimensional resistivity structure model
}

\author{
Wataru Kanda ${ }^{*} \mathbb{0}$, Mitsuru Utsugi ${ }^{2}$, Shinichi Takakura ${ }^{3}$ (10 and Hiroyuki Inoue ${ }^{2}$
}

\begin{abstract}
During the past two decades, studies of the Aso volcano in Japan have improved our understanding of the shallow hydrothermal system that exists beneath the active crater of this volcano. Detailed knowledge of the subsurface structure of this volcanic edifice is essential for developing a better understanding of the behavior of the volcanic fluids and of the triggering mechanism of volcanic eruptions. Here, we report a three-dimensional (3-D) electrical resistivity model for the active crater of the Nakadake central cone of Aso volcano using audio-frequency magnetotelluric (AMT) data obtained during 2004-2005. The AMT data were collected at 43 sites on a grid (distance between grid points: $\sim 300 \mathrm{~m}$ ) around the crater. However, as yet, only two-dimensional sectional resistivity models have been generated for this survey area. Using 3-D inversion, we obtain a resistivity model that shows similar characteristics to those of the 2-D models. A highly conductive zone is observed beneath the active crater down to a depth of approximately $300 \mathrm{~m}$. Based on the recent findings regarding the shallow hydrothermal system of the volcano, we interpret this conductive zone to have been formed by highly conductive acidic fluids filling a fractured region. This view modifies the past interpretation made on the 2-D models and promotes understanding of fluid behavior beneath the active crater.
\end{abstract}

Keywords: Resistivity structure, Audio-frequency magnetotellurics, Three-dimensional inversion, Hydrothermal system, Aso volcano

\section{Introduction}

Knowledge on the subsurface structure is essential for a better understanding of the volcanic activity. In particular, the triggering mechanism and/or the style of eruptions greatly depend on whether the fluid within the volcanic edifice is involved or not (e.g., Schmincke 2004). Distribution and behavior of the fluid within a volcano is regulated by the hydrothermal system developed in the shallow subsurface, and electrical resistivity has often been used to determine its characteristics (e.g., Pellerin et al. 1996). This paper provides basic information on

\footnotetext{
*Correspondence: kanda@ksvo.titech.ac.jp

${ }^{1}$ Volcanic Fluid Research Center, School of Science, Tokyo Institute of Technology, 641-36 Kusatsu, Agatsuma, Gunma 377-1711, Japan Full list of author information is available at the end of the article
}

the structure of hydrothermal system from the detailed resistivity distribution beneath the active crater of Aso volcano.

Aso volcano in southwestern Japan (Fig. 1a, b) has registered repeated eruptions from the first crater of Nakadake, one of the volcano's central cones, over the past 80 years. The volcanic activity is known to have the following cycle (e.g., Sudo et al. 2006). During a quiet period, the active crater (first crater) is filled with hot hyperacidic water (water temperature $>50{ }^{\circ} \mathrm{C}$, $\mathrm{pH}<1.0$; Ohsawa et al. 2010), forming a crater lake. As the volcanic activity increases, the crater lake gradually dries as a result of heat supplied from the deep subsurface, and a red-hot glow becomes visible in the bottom or wall of the crater. Then, the vent opens and phreatic eruptions or mud eruptions occur. After repeating the 

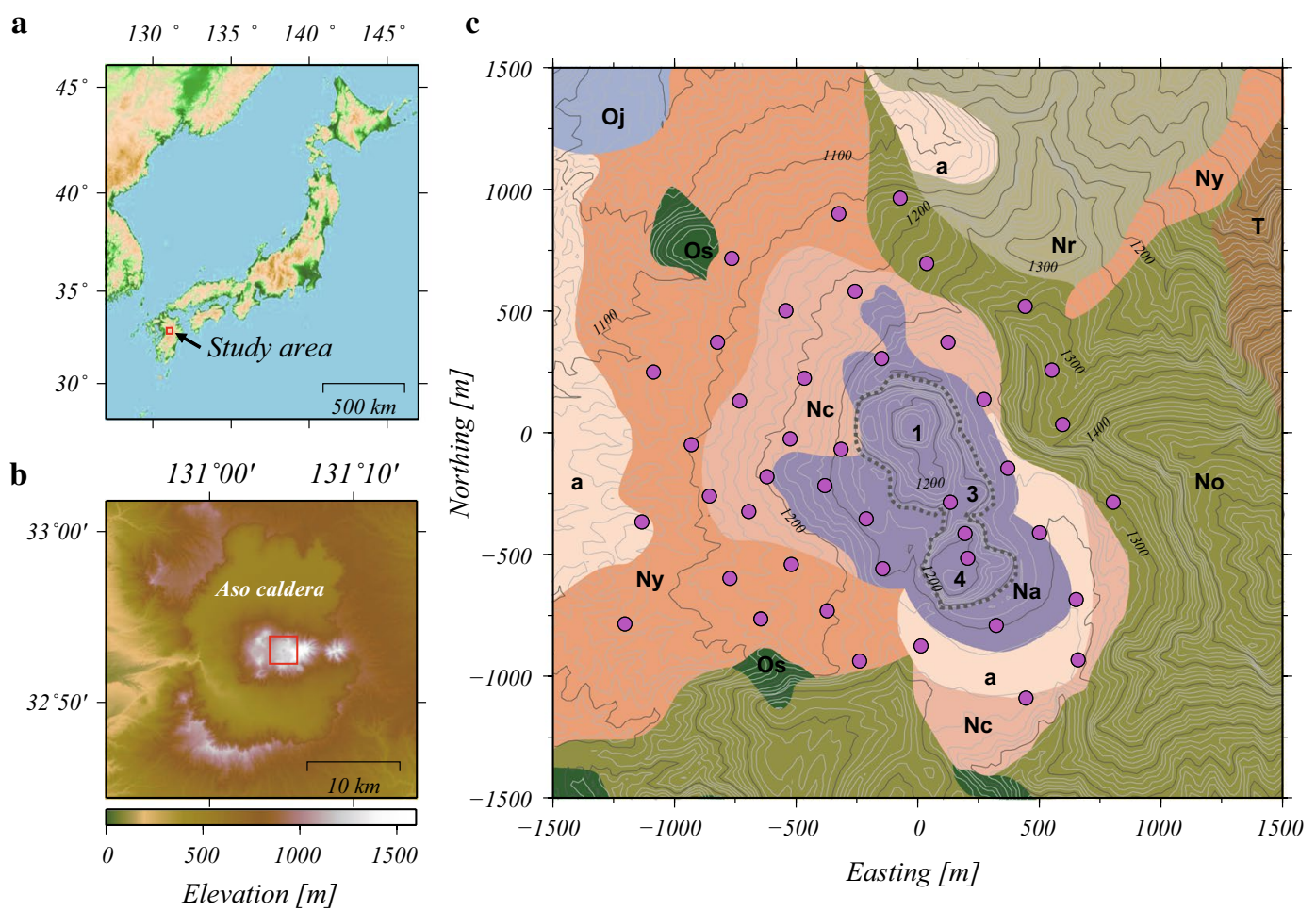

Fig. 1 Location maps of Aso volcano and the AMT survey area. a Location map of Aso volcano in Japan. The red rectangle corresponds to the area shown in (b). $\mathbf{b}$ Elevation map of the entire area of Aso volcano. The study area is indicated by the red rectangle, corresponding to the area shown in (c). c Geological map of the study area (after Ono and Watanabe 1985) showing the distribution of AMT sites (purple circles) used in this study. The lithologies are as follows (from youngest to oldest). a: air-fall ash; Na: youngest pyroclastic cone of Nakadake; Ny (lava flow) and Nc (tuff cone): young volcanic edifice of Nakadake; No: old volcanic edifice of Nakadake; Oj: Ojodake volcano; T: Takadake volcano; Nr: Naraodake volcano; and Os: older small volcanoes. The gray dotted line represents the outline of the Nakadake crater system, and the numbers $(1,3$, and 4$)$ within it indicate the locations of the first, third, and fourth craters, respectively. The thin gray lines and thick gray lines represent elevations at 10-m and 50-m intervals, respectively

Strombolian-type eruption for a period, the volcano again forms a crater lake. The time scale of this activity cycle is different in each case.

Kanda et al. (2008) presumed that some mechanism of accumulating energy for an eruption must be present at a shallow depth beneath the crater in order to repeat such an activity cycle and that such a mechanism should be detectable physically as a characteristic subsurface structure. In this context, the authors performed audio-frequency magnetotelluric (AMT) surveys on Aso volcano in 2004 and 2005. The data were acquired on a grid around the Nakadake crater system, but only twodimensional (2-D) cross sections along multiple lines crossing the crater were constructed because it was difficult to perform three-dimensional (3-D) analysis at that time. Kanda et al. (2008) found that the volcanic edifice generally showed resistivities lower than $30-50 \Omega \mathrm{m}$, with further conductive portions being found at elevations of $800-1100 \mathrm{~m}$ below the first crater and extending to the third crater, and at elevations ranging from
-400 to $800 \mathrm{~m}$. In contrast, relatively high resistivities were detected under the fourth crater, which is not presently active. Kanda et al. (2008) discussed this difference in resistivity structure in terms of spatial variations in recent and present volcanic activity.

Several recent studies of Aso volcano have investigated the crater lake, one of the surface manifestations of the hydrothermal system. Miyabuchi and Terada (2009) analyzed lacustrine sediments collected from the bottom of the crater lake and found that the total sulfur content of the sediments was extremely high. The sediments contained small amounts of unaltered fresh glass, suggesting that magma had been released even during apparently quiet periods. Terada et al. (2012) studied the hydrothermal system of the volcano by investigating the heat and mass balances of the crater lake. Fluids composed of a mixture of groundwater and high-temperature volcanic gases ascend through a crack-like conduit, which was inferred to be a source of long-period tremors (Yamamoto et al. 1999), and are continuously supplied to the 
crater bottom even during quiet periods. Shinohara et al. (2018) analyzed salt shell fallout around the crater during the 2014 ash eruption and surmised that a hydrothermal system was present in the vicinity of the conduit even during the period of magmatic eruption.

As mentioned above, new information regarding the hydrothermal system has been generated since the publication of the 2-D resistivity structure models in 2008 . Thus, it is timely to update the subsurface images around the crack-like conduit beneath the active crater (first crater) of Aso into a 3-D model by reanalyzing the AMT data obtained near the Nakadake crater system in 2004 and 2005. The objective of this study is to construct the 3 -D resistivity structure model and interpret it based on the recent information.

\section{Data}

AMT surveys were conducted around the Nakadake crater system in 2004 and 2005. Details of those campaigns and data processing are described by Kanda et al. (2008). Here, we briefly summarize the survey scheme. Figure 1c shows the location of the measurement sites used in this study, which are distributed on a sub-grid with a spacing of $\sim 300 \mathrm{~m}$. Of the data obtained at 44 AMT measurement sites, we used the data $(1-10,000 \mathrm{~Hz})$ at 43 sites, excluding one site where contamination by artificial noise was recognized even in high-frequency bands. High-quality data were generally obtained at frequencies higher than $5 \mathrm{~Hz}$, but some data show the influence of noise caused by nearby buried communication cables or by sightseeing ropeways installed on the volcanic edifice. These affected data were not used during subsequent screening and analysis. The magnetotelluric impedance and the geomagnetic transfer function (tipper) were estimated from the measured electromagnetic field data, and a remote-referencing technique (Gamble et al. 1979) was applied to reduce local noise. This processing allowed us to use data with frequencies of $>2 \mathrm{~Hz}$ at many sites.

\section{3-D inversion}

There are three measurement sites within the crater system, around which there is steep topography. Therefore, we performed 3-D inversion with a finite element code utilizing an unstructured tetrahedral mesh that can incorporate topography into a resistivity model (FEMTIC; Usui 2015; Usui et al. 2017). This code has been applied successfully to volcanic areas at Asama volcano (Usui et al. 2017) and Hakone volcano (Yoshimura et al. 2018).

The full components of the impedance tensor and tipper were used as the input data for inversion. The error floor was set to $5 \%$ for impedance and $10 \%$ for tipper. The number of frequencies used for computation was
16, ranging from $5200 \mathrm{~Hz}$ to $2 \mathrm{~Hz}$, which was sampled so as to yield approximately equal intervals on the logarithmic axis among the 40 frequencies at which the response function was calculated. Therefore, the total number of input data was 43 (sites) $\times 16$ (frequencies) $\times 12$ (real and imaginary parts of 4 impedance components and 2 tipper components) $=8256$.

The calculation domain was set to $40 \mathrm{~km}$ in both the east-west and north-south directions, centered on Nakadake first crater, and $60 \mathrm{~km}$ in the vertical direction. The initial model had a $100 \Omega \mathrm{m}$ uniform subsurface, and topographic variations were incorporated into the model. The ocean with conductive seawater was not modeled because the maximum skin depth of the data assuming a $1000 \Omega \mathrm{m}$ uniform subsurface is much smaller than the distance from the surveyed area to the nearest coastline. The resistivity of the domain above the ground surface (air layer) was fixed at $10^{9} \Omega \mathrm{m}$. Two types of digital elevation data were used: The 10-m-mesh data of the Geospatial Information Authority of Japan was used for the area within $10 \mathrm{~km}$ of the first crater, and ETOPO-1 (Amante and Eakins 2009) was used for areas farther from the crater. An interpolated elevation was assigned to each surface node for the two datasets. The mesh size was set to smaller values toward the center of the calculation area and toward the ground surface and was set even more finely near the measurement sites (Fig. 2). In other words, we assigned the edge lengths of a tetrahedral element so as to become shortened as approaching the center of the survey area. As a result, the total number of tetrahedral mesh cells was 137,598 and the minimum size of the mesh was about $40 \mathrm{~m}$ along the ground surface. In FEMTIC, resistivity inside a tetrahedral mesh is assumed to be uniform. A single tetrahedron has a single resistivity value, but some of the adjacent tetrahedrons were grouped (forming a resistivity block), and the same resistivity value was assigned to that block. Consequently, the number of resistivity blocks was 10,814, which was fixed throughout the inversion.

During inversion, the objective function, which is a linear combination of the misfit term between the observed data and the model responses, the roughness term of the model, and the distortion term, is minimized (Usui 2015). These three terms are combined by hyper-parameters $\alpha^{2}$ and $\beta^{2}$, where the roughness term and the distortion term are multiplied by $\alpha^{2}$ and $\beta^{2}$, respectively. Thus, we examined seven values $(0.1,0.3,0.5,1.0,3.0,5.0$, and 10.0$)$ for $\alpha^{2}$ and four values $(0.01,0.03,0.1$, and 0.3$)$ for $\beta^{2}$. That is, inversion was performed for a total of 28 combinations of hyper-parameters. The determination of $\alpha^{2}$ was performed under the L-curve criterion, as done previously (e.g., Patro et al. 2005; Usui et al. 2017). For the seven models obtained by changing $\alpha^{2}$ with a given $\beta^{2}$ value, 


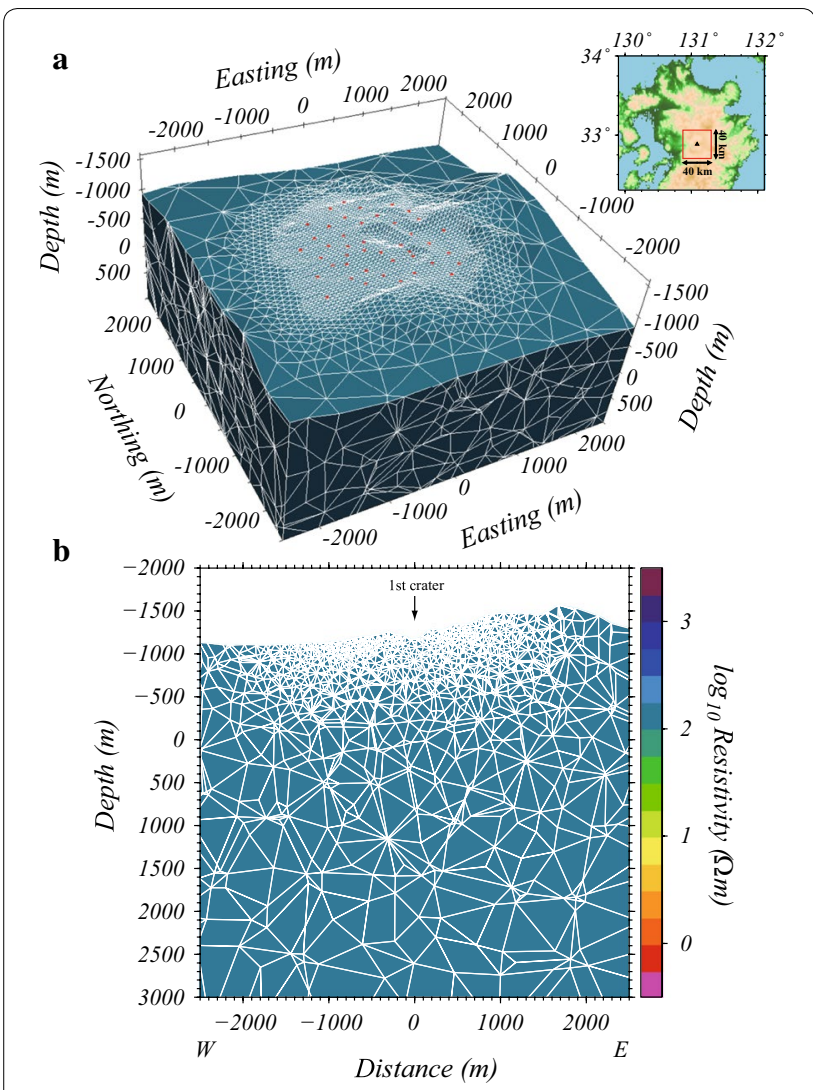

Fig. 2 Distribution of the tetrahedral mesh used for 3-D inversion in the survey area. a Surface mesh over an area of $5 \mathrm{~km} \times 5 \mathrm{~km}$ centered on the Nakadake first crater. The red dots indicate AMT sites. A resistivity value of $100 \Omega \mathrm{m}$ was given for each mesh cell as a starting model. The mesh for the air layer has been omitted to enhance the clarity of the graphic. $\mathbf{b}$ East-west cross section passing through the origin (the center of the Nakadake first crater). The mesh cell size is smaller closer to the ground and closer to the central area

the data misfit was plotted against the model roughness, and the model that plotted nearest the inflection point of the L-curve was adopted as the preferred model. Regardless of the $\beta^{2}$ value, the L-curve showed that the model with $\alpha^{2}=0.5$ was the preferred model. The L-curves for four $\beta^{2}$ values are shown in Additional file 1: Fig. S1. Of the four models with $\alpha^{2}=0.5$, the model with $\beta^{2}=0.03$ yielded the minimum root-mean-square (RMS) misfit, so this model $\left(\alpha^{2}=0.5, \beta^{2}=0.03\right)$ was adopted as the final resistivity structure model for Aso volcano.

Starting from the initial model (RMS misfit $=7.45)$, the final model was obtained by the ninth iteration (RMS misfit $=0.88$ ). The fitting of the final model to the data is shown in Fig. 3 for three representative frequencies. Figure 3 shows the elliptical representation of the phase tensor (Caldwell et al. 2004) calculated from all four components of the impedance tensor and the induction arrow (Parkinson 1962), which is a graphical representation of the two tipper components. The final model performs well in explaining all data from high to low frequencies. Fits represented by apparent resistivity, phase, and tipper for all frequencies used for the inversion are shown in Additional file 1: Fig. S2a-e.

\section{3-D model}

Figure 4 shows horizontal sections of the final 3-D resistivity model for six elevations. The figure shows only those meshes that have higher sensitivity and sensitivity density (Usui 2015) than the threshold values, which were determined based on the frequency distribution (Usui et al. 2017; Yoshimura et al. 2018). Histograms of the two quantities and their thresholds are presented in Additional file 1: Fig. S3.

In the horizontal section at $1200 \mathrm{~m}$ elevation, highly conductive zones are observed around the eastern margin of the survey area and within the first crater. For the conductor in the eastern margin of the survey area, although we examined various data, the cause has remained unknown and we will not mention it further in this paper. Although low resistivities are also distributed around the margin of Nakadake crater system, high resistivities of up to several hundred ohm-meters are widespread outside the crater. High resistivities are imaged at $\sim 1200 \mathrm{~m}$ in elevation in the northwest of the crater, which are likely to correspond to the recent pyroclastic cone ( $\mathrm{Na}$ in Fig. $1 \mathrm{c})$ and the tuff cone $(\mathrm{Nc})$ near the surface.

In the section at $1000 \mathrm{~m}$ elevation, although resistive zones probably corresponding to the lava flow of Nakadake (Ny) can be recognized, low resistivities of $10-50 \Omega \mathrm{m}$ occur widely over the surveyed area. In particular, there is a low-resistivity zone of $\leq 5 \Omega \mathrm{m}$ extending westward from the first crater, and a similar small zone is located to the southwest of the fourth crater. These two conductive zones are connected to each other to form a single conductive zone of $\leq 10 \Omega \mathrm{m}$ in the section at $800 \mathrm{~m}$ elevation, in which the whole survey area exhibits resistivities of $\leq 50 \Omega \mathrm{m}$, and conductive zones of $\leq 10 \Omega \mathrm{m}$ are found in four locations.

In the section at $600 \mathrm{~m}$ elevation, the resistivity is low overall, and resistivity regions of $\leq 10 \Omega \mathrm{m}$ occupy the majority of the survey area. One of these low-resistivity regions shows resistivities of $\leq 5 \Omega \mathrm{m}$ slightly west of the first crater, whereas a region of relatively high resistivity (10-30 $\Omega \mathrm{m})$ extends southward from the fourth crater. This pattern becomes more prominent in lower-elevation sections. At an elevation of $300 \mathrm{~m}$, a region with relatively high resistivities (10-30 $\Omega \mathrm{m}$ ) spreads from the south to the east of the fourth crater, and the remainder of the section generally shows resistivities of $\leq 10 \Omega \mathrm{m}$. In particular, a highly conductive region (resistivity of $\leq 5 \Omega \mathrm{m}$ ) 

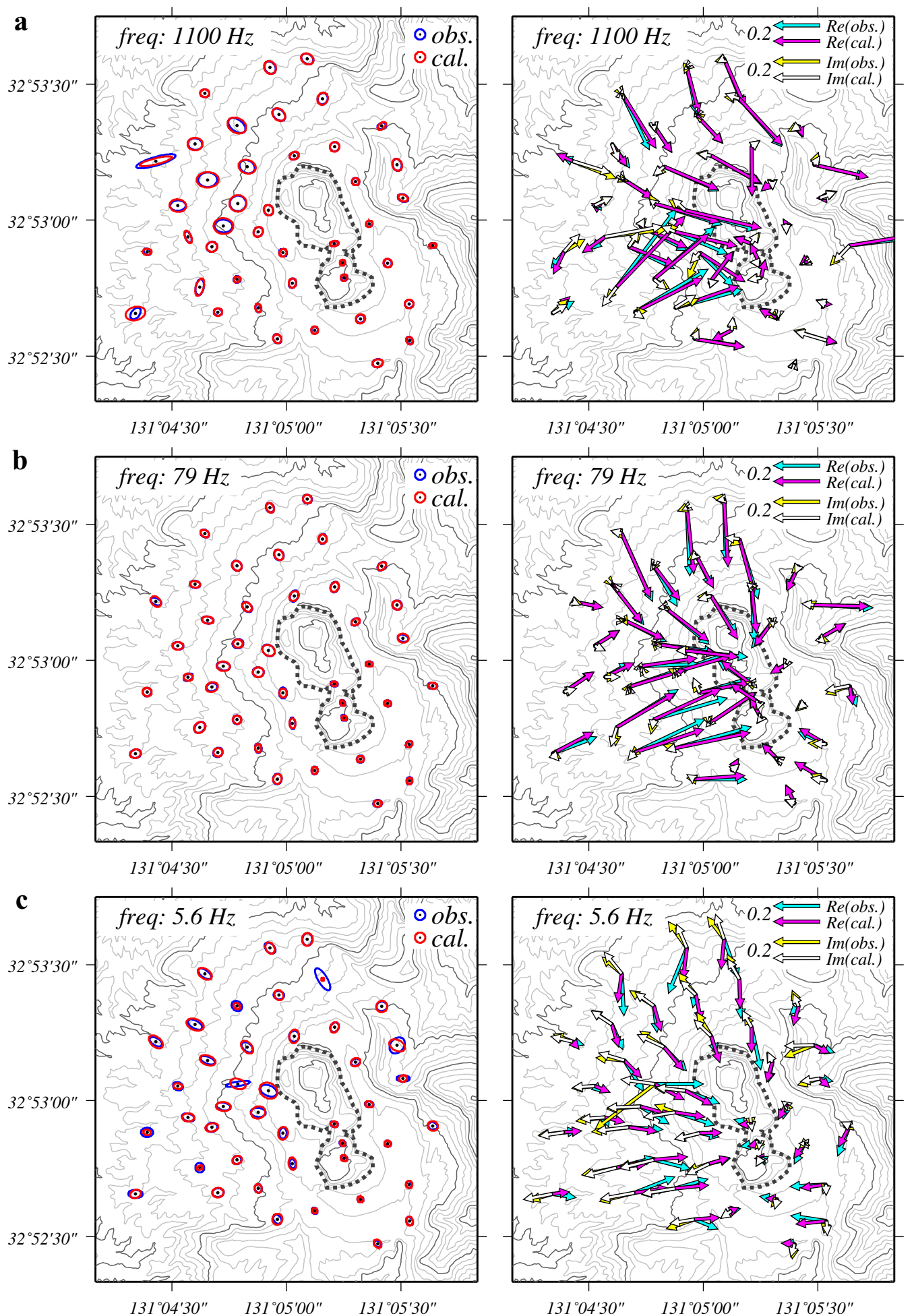

Fig. 3 Comparisons of observed data with the results of the final 3-D resistivity model for three representative frequencies. a Comparison of the phase tensor (left) and induction arrows (right) at $1100 \mathrm{~Hz}$. The left-hand panel shows the elliptical representation of the phase tensor (Caldwell et al. 2004). The right-hand panel shows the real and imaginary induction arrows (Parkinson 1962). b Comparison of the phase tensor (left) and induction arrows (right) at $79 \mathrm{~Hz}$. c Comparison of the phase tensor (left) and induction arrows (right) at $5.6 \mathrm{~Hz}$ 

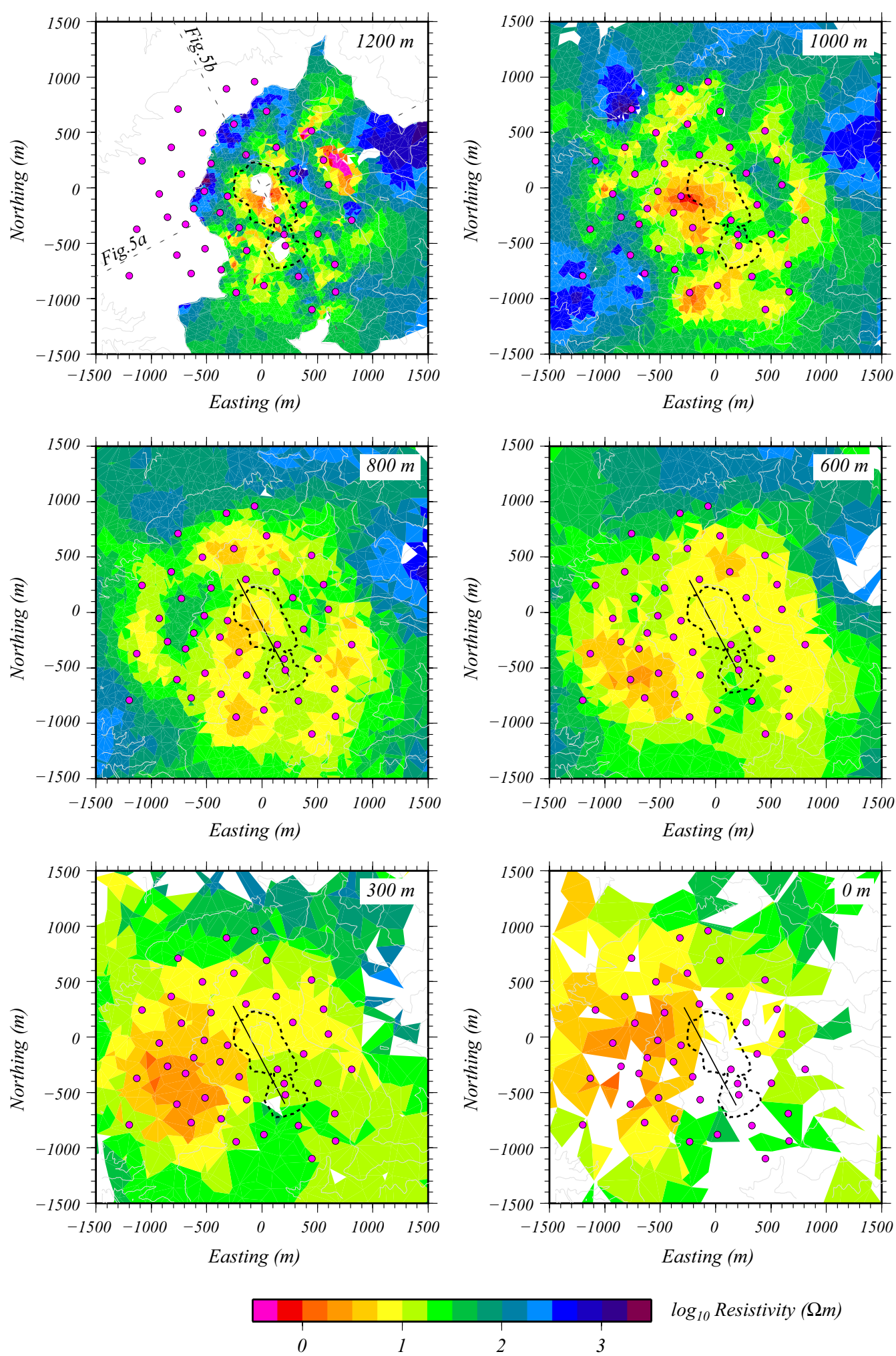

$\log _{10}$ Resistivity $(\Omega m)$

Fig. 4 Horizontal sections of the final 3-D resistivity model for six different elevations. Horizontal sections of resistivity for elevations of 1200, 1000, $800,600,300$, and $0 \mathrm{~m}$. The dashed line in each diagram indicates the projection of the outline of the Nakadake crater system. The solid line shown in the diagrams for 800,600,300, and $0 \mathrm{~m}$ represents the intersection of each section with the crack-like conduit reported by Yamamoto et al. (1999). The red circles indicate AMT sites 
is located to the west of the first crater. A similar pattern can be recognized at an elevation of $0 \mathrm{~m}$, although about half of the mesh shows no sensitivity. These characteristics indicated by the 3-D resistivity model are consistent with those shown by the 2-D cross-sectional models of Kanda et al. (2008), and some of which were examined for their presence by performing sensitivity tests. Details are shown in Additional file 2: Appendix A.

\section{Discussion}

The final 3-D model exhibits a heterogeneous resistivity structure beneath the active crater of Aso volcano. Generally, the surface layer shows high resistivity caused by recent ejecta, whereas low resistivities are widely distributed beneath that layer. However, the resistivity structure is not uniform: the region to the west of the first crater shows low resistivities, whereas the region to the south and east of the fourth crater shows relatively high resistivities. Here, we discuss the relationship between the locations of various anomalies (as estimated from other geophysical observations) and the underground structure and consider the characteristics of the hydrothermal system in the region beneath the active crater.

Seismological studies have proposed a magma supply system for Aso volcano extending from a magma reservoir located at a depth of $\sim 6 \mathrm{~km}$ about $3 \mathrm{~km}$ west of the Nakadake crater system (Tsutsui and Sudo 2004; Sudo et al. 2006). The crack-like conduit (shown as a solid line in Fig. 4) constitutes the uppermost part of this magma supply system and inferred to be filled with a gas-rich fluid (Yamamoto et al. 1999). The 3-D model shows low resistivities of $\leq 10 \Omega \mathrm{m}$ at elevations where this cracklike conduit is proposed $(0-800 \mathrm{~m}$ above sea level), although clear features suggesting the existence of the crack are not obtained. We attribute this conductive zone to the presence of a water-rich zone and altered rocks, as proposed by Kanda et al. (2008). A highly conductive region is imaged in the deep part of the west side of the Nakadake crater system, which is probably related to the seismologically inferred magma supply system through which high-temperature volcanic gases are supplied from the west. The expected higher temperatures beneath the western side are likely to cause a zone of intensive hydrothermal alteration (Kanda et al. 2008).

Low resistivities of several ohm-meters are estimated in the final model to extend from around the upper edge of the crack-like conduit to the bottom of the first crater (from about 850 to $1200 \mathrm{~m}$ in elevation; Figs. 4 and 5). Kanda et al. (2008) inferred that this highly conductive region was a hydrothermal reservoir capped with hydrothermally altered rocks of high electrical conductivity and low hydrological permeability. Those authors considered that this capped reservoir acts as a preparation zone for volcanic explosions. Miyabuchi and Terada (2009) reported a high sulfur content ( $74 \%$ by weight) in the lacustrine sediments. This sulfur was present as elemental sulfur, gypsum, and anhydrite. Sulfur is a typical insulator, and the two sulfates are generated in highly acidic environments and exhibit high electrical resistivity (e.g., Guinea et al. 2012). In such highly acidic environments, smectite, which is a typical clay mineral showing low resistivity and low permeability (e.g., Pellerin et al. 1996), is considered to be virtually absent. A similar example is found in the Jigokudani geothermal area of Tateyama volcano (Japan), where AMT measurements imaged high conductivities in the near-surface; however, the soil contained elemental sulfur and similar precipitates generated in a highly acidic environment $(\mathrm{pH} \sim 1)$, and smectite has not been detected at Jigokudani (Seki et al. 2016).

Several kinds of tremors are reported to occur around the upper edge of the crack-like conduit and are considered to be a result of fluid movement (e.g., Mori et al. 2008). A study of continuous tremors (CTs) has shown that their sources are located between the upper part of the crack-like conduit and the crater bottom (e.g., Takagi et al. 2009). Ichimura et al. (2018) estimated the sources of CTs observed during the eruptive activity of Aso volcano from December 2013 to January 2014. The CT sources were distributed in a cylindrical shape with a similar diameter to that of the first crater from the crater bottom to a depth of $\sim 400 \mathrm{~m}$. As this source region corresponds to the low-resistivity zone estimated by Kanda et al. (2008), Ichimura et al. (2018) concluded that the CT source region is composed of a fracture network that acts as a supply path for fluids ascending from the cracklike conduit to the crater bottom. It was also inferred from other data that a certain amount of fluids is present beneath the first crater (Terada et al. 2012; Tanaka 1993). Terada et al. (2012) found that the fluid supplied to the crater bottom was a mixture of high-temperature volcanic gases and groundwater at shallow depths. It has also been suggested from geomagnetic observations that groundwater enables heat transfer in the thermally demagnetized source at 200-300 m below the crater bottom (Tanaka 1993).

Based on the above results, the high-conductivity zone that extends from the crack-like conduit to the crater bottom is considered to be due mainly to the high electrical conductivity of the acidic hydrothermal fluid. Although the electrical conductivity of lake water has not been measured so far, it is expected to have a considerably high value due to its high ion concentration and low pH (e.g., Ohsawa et al. 2010). Byrdina et al. (2018) estimated the theoretical electrical conductivity of spring waters sampled at Papandayan volcano (Indonesia) to be extremely high values of $20-25 \mathrm{~S} / \mathrm{m}$ from their chemical 

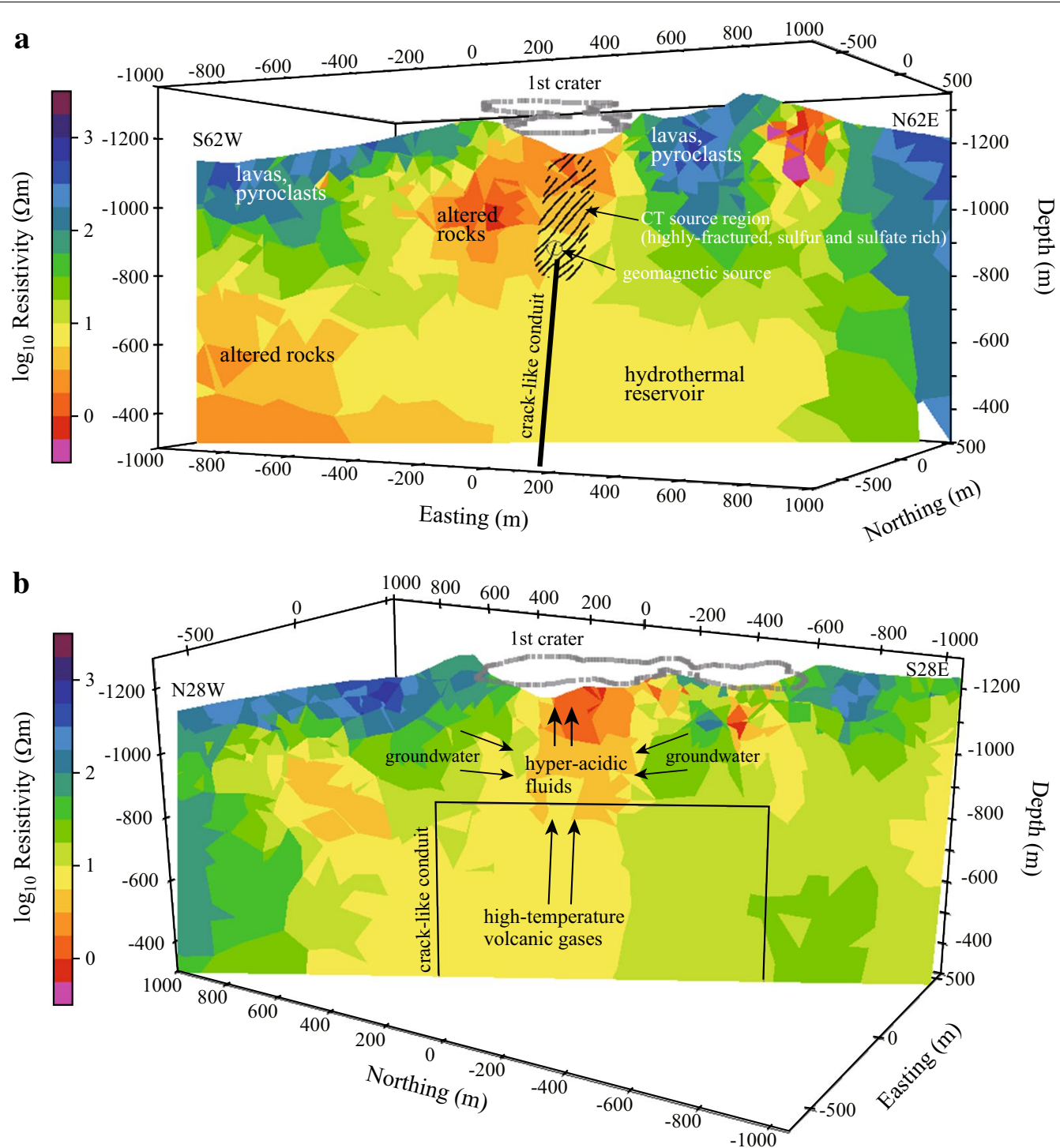

Fig. 5 Interpretation of the 3-D resistivity model. a Vertical section through the first crater perpendicular to the strike of the crack-like conduit (Yamamoto et al. 1999). The CT source region and the geomagnetic source are drawn based on Ichimura et al. (2018) and Tanaka (1993), respectively. $\mathbf{b}$ Sub-vertical section along the surface of the crack-like conduit. Flows of interpreted hydrothermal fluids are indicated by arrows

compositions and $\mathrm{pH}$ values. Using the compositional data shown in Miyabuchi and Terada (2009), we estimated the electrical conductivity of lake water in the Nakadake first crater to be $\sim 40 \mathrm{~S} / \mathrm{m}$ by the same method (details are shown in Additional file 2: Appendix B). Although this exceptionally high value is likely to be an overestimate as pointed out by Byrdina et al. (2018) for waters of high ion concentrations, the order of magnitude would not be different because high values exceeding 10 $\mathrm{S} / \mathrm{m}$ were sometimes measured for hot-spring waters in the volcanic area (e.g., Seki et al. 2016). If such high-conductivity fluids infiltrate the inter-connected fractures, the influence of sulfur or sulfates with high resistivity to the bulk conductivity of rocks can be neglected (e.g., Guinea et al. 2012; Byrdina et al. 2018). There is no evidence that altered rocks with high electrical conductivity, as proposed by Kanda et al. (2008), occupy the region beneath the crater bottom.

The existence of a sulfur-rich region immediately below the crater bottom is commonly reported in highly acidic crater lakes (e.g., Delmelle and Bernard 2015). Christenson et al. (2010) inferred that a region rich in elemental sulfur was present around the conduit and the bottom of Ruapehu crater lake (New Zealand), where a 
phreatomagmatic eruption occurred in 2007, and contended that the sulfur acted as a low-permeability seal. We consider that a similar situation exists at the active crater of Aso volcano (Fig. 5). Although such resistive minerals are precipitated at Aso, the intermittent high flux of high-temperature gas supplied through the cracklike conduit could break the seals formed around the fractures, which might be observed as the occurrence of repeated tremors. As a result, a highly fractured region with high conductivity is considered to be present immediately below the first crater.

\section{Conclusion}

In this study, AMT data acquired between 2004 and 2005 were reanalyzed using a recently developed 3-D inversion code to estimate the detailed shallow resistivity structure of Aso volcano. The obtained resistivity model shows similar characteristics to those of the 2-D cross sections presented by Kanda et al. (2008). In the previous 2-D analysis, it was not possible to estimate the influence of 3 -D topography. However, in the present study we incorporated detailed topography into the model and therefore the obtained resistivity structure around the crater is more reliable. Combining our results with recent findings regarding the hydrothermal system of the volcano, we infer that the region from the upper end of the cracklike conduit to the bottom of the first crater exhibits high conductivities because this region is highly fractured and filled with acidic hydrothermal fluids. Therefore, we consider that the hydrothermal system beneath the active crater of Aso volcano effectively forms an open system. Although sulfur and sulfate minerals precipitated around the fluid pathway act as seals reducing permeability, those seals are probably broken with causing several kinds of tremors by the continuous fluid supply from the crack-like conduit. When the volcanic activity becomes active caused by the increase in fluid flux from the deep, this system would virtually work as a closed system to lead to eruptions.

\section{Additional files}

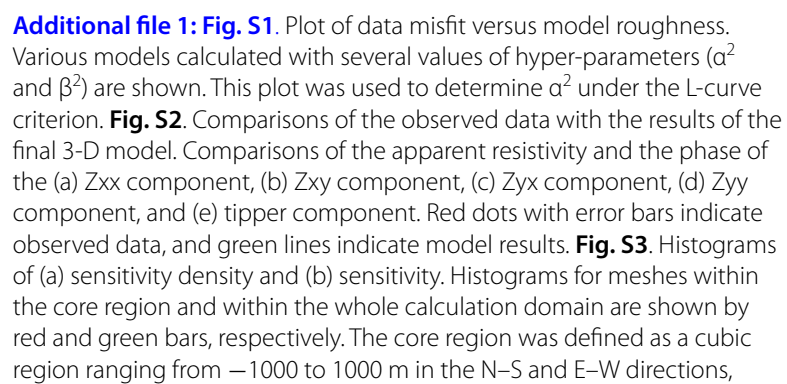

and from -2000 to $0 \mathrm{~m}$ in the vertical direction, which covers most of the AMT survey area. The vertical dashed line in each histogram indicates the lower limit of the relatively sensitive mesh $\left(10^{-6.4}\right.$ for sensitivity density and $10^{0.5}$ for sensitivity), which was determined so as to contain most of the mesh of the core region.

Additional file 2: Appendix A. Sensitivity test. Appendix B. Estimation of the electrical conductivity of lake water.

\section{Abbreviations \\ AMT: audio-frequency magnetotelluric; 2-D: two-dimensional; 3-D: three- dimensional; CT: continuous tremor; RMS: root-mean-square.}

\section{Authors' contributions}

WK led the AMT acquisition, data analysis, and 3-D modeling. MU, ST, and $\mathrm{HI}$ played leading roles in the field work. WK, MU, and ST participated in the scientific discussions. All authors read and approved the final manuscript.

\section{Author details}

${ }^{1}$ Volcanic Fluid Research Center, School of Science, Tokyo Institute of Technology, 641-36 Kusatsu, Agatsuma, Gunma 377-1711, Japan. ${ }^{2}$ Aso Volcanological Laboratory, Institute for Geothermal Sciences, Kyoto University, 3028 Sakanashi, Aso, Kumamoto 869-2611, Japan. ${ }^{3}$ Geological Survey of Japan, National Institute of Advanced Industrial Science and Technology (AIST), 1-1-1 Higashi, Tsukuba, Ibaraki 305-8567, Japan.

\section{Acknowledgements}

We thank all participants of the field survey (Y Tanaka, M Nakaboh, H Hiura, T Mori, S Yoshikawa, S Goto, and Y Okada). We also thank Y Usui, for the use of his 3-D inversion code. The constructive comments provided by the two reviewers (Paul A. Bedrosian and anonymous) and the Lead Guest Editor (Takahiro Ohkura) were highly helpful to improve the manuscript. Numerical calculations were performed with the TSUBAME3.0 supercomputer at the Tokyo Institute of Technology. Most of the figures were prepared using Generic Mapping Tools (Wessel and Smith 1998).

\section{Competing interests}

The authors declare that they have no competing interests.

\section{Availability of data and materials}

All data are presented as diagrams in Additional file 1: Figure S2. The data that support the findings of the present study are available from the corresponding author upon request.

\section{Consent for publication \\ Not applicable}

Ethics approval and consent to participate Not applicable

\section{Funding}

The original AMT dataset was acquired under a Grant-in-Aid for Scientific Research on Priority Areas (No. 14080205: Y Tanaka). This study was partially funded by the MEXT Integrated Program for Next Generation Volcano Research and Human Resource Development (Y Morita).

\section{Publisher's Note}

Springer Nature remains neutral with regard to jurisdictional claims in published maps and institutional affiliations.

Received: 31 October 2018 Accepted: 21 March 2019

Published online: 10 April 2019

\section{References}

Amante C, Eakins BW (2009) ETOPO1 1 arc-minute global relief model: Procedures, data sources and analysis. NOAA Technical Memorandum 
NESDIS NGDC-24, National Geophysical Data Center, NOAA. https://doi. org/10.7289/v5c8276m

Byrdina S et al (2018) Structure of the acid hydrothermal system of Papandayan volcano, Indonesia, investigated by geophysical methods. J Volcanol Geotherm Res 358:77-86. https://doi.org/10.1016/j.jvolgeores .2018.06.008

Caldwell TG, Bibby HM, Brown C (2004) The magnetotelluric phase tensor. Geophys J Int 158:457-469. https://doi.org/10.1111/j.1365246X.2004.02281.X

Christenson BW et al (2010) Cyclic processes and factors leading to phreatic eruption events: insights from the 25 September 2007 eruption through Ruapehu Crater Lake, New Zealand. J Volcanol Geotherm Res 191:15-32. https://doi.org/10.1016/j.jvolgeores.2010.01.008

Delmelle P, Bernard A (2015) The remarkable chemistry of sulfur in hyperacid crater lakes: a scientific tribute to Bokuichiro Takano and Minoru Kusakabe. In: Rouwet D, Christenson B, Tassi F, Vandemeulebrouck J (eds) Volcanic lakes. Springer, Berlin. https://doi.org/10.1007/978-3-642-36833 $-2 \_10$

Gamble TD, Goubau WM, Clarke J (1979) Magnetotellurics with a remote magnetic reference. Geophysics 44:53-67. https://doi.org/10.1190/1.1440923

Guinea A, Playa E, Rivero L, Ledo JJ, Querat P (2012) The electrical properties of calcium sulfate rocks from decametric to micrometric scale. J Appl Geophys 85:80-91. https://doi.org/10.1016/j.jappgeo.2012.07.003

Ichimura M, Yokoo A, Kagiyama T, Yoshikawa S, Inoue H (2018) Temporal variation in source location of continuous tremors before ash-gas emissions in January 2014 at Aso volcano. Japan. Earth Planets Space 70:125. https:// doi.org/10.1186/s40623-018-0895-4

Kanda W et al (2008) A preparation zone for volcanic explosions beneath Naka-dake crater, Aso volcano, as inferred from magnetotelluric surveys. J Volcanol Geotherm Res 178:32-45. https://doi.org/10.1016/j.jvolgeores 2008.01.022

Miyabuchi Y, Terada A (2009) Subaqueous geothermal activity revealed by lacustrine sediments of the acidic Nakadake crater lake, Aso Volcano, Japan. J Volcanol Geotherm Res 187:140-145. https://doi.org/10.1016/j. jvolgeores.2009.08.001

Mori T, Sudo Y, Tsutsui T, Yoshikawa S (2008) Characteristics of isolated hybrid tremor (HBT) during a calm activity period at Aso Volcano. Bull Volcanol 70:1031-1042. https://doi.org/10.1007/s00445-007-0185-7

Ohsawa S et al (2010) Color change of lake water at the active crater lake of Aso volcano, Yudamari, Japan: is it in response to change in water quality induced by volcanic activity? Limnology 11:207. https://doi.org/10.1007/ s10201-009-0304-6

Ono K, Watanabe K (1985) Geological map of Aso volcano (1:50,000). Geological map of volcanoes 4, Geological Survey of Japan (in Japanese with English abstract)

Parkinson WD (1962) The influence of continents and oceans on geomagnetic variations. Geophys J R Astron Soc 6:441-449. https://doi.org/10.1111/ j.1365-246X.1962.tb02992.x
Patro BPK, Brasse H, Sarma SVS, Harinarayana T (2005) Electrical structure of the crust below the Deccan Flood Basalts (India), inferred from magnetotelluric soundings. Geophys J Int 163:931-943. https://doi.org/10.1111/j.1365246X.2005.02789.x

Pellerin L, Johnston JM, Hormann GW (1996) A numerical evaluation of electromagnetic methods in geothermal exploration. Geophysics 61:121130. https://doi.org/10.1190/1.1443931

Schmincke H-U (2004) Volcanism. Springer, Heidelberg, pp 1-324

Seki K et al (2016) Resistivity structure and geochemistry of the Jigokudani Valley hydrothermal system, Mt. Tateyama. Japan. J Volcanol Geotherm Res 325:15-26. https://doi.org/10.1016/j.jvolgeores.2016.06.010

Shinohara H, Geshi N, Yokoo A, Ohkura T, Terada A (2018) Salt shell fallout during the ash eruption at the Nakadake crater, Aso volcano, Japan: evidence of an underground hydrothermal system surrounding the erupting vent. Earth Planets Space 70:46. https://doi.org/10.1186/s40623-018-0798-4

Sudo $Y$ et al (2006) Ground deformation and magma reservoir at Aso Volcano: Location of deflation source derived from long-term geodetic surveys. Bull Volcanol Soc Jpn 51:291-309 (in Japanese with English abstract)

Takagi N, Kaneshima S, Ohkura T, Yamamoto M, Kawakatsu H (2009) Long-term variation of the shallow tremor sources at Aso Volcano from 1999 to 2003. J Volcanol Geotherm Res 184:333-346. https://doi.org/10.1016/j. jvolgeores.2009.04.013

Tanaka Y (1993) Eruption mechanism as inferred from geomagnetic changes with special attention to the $1989-1990$ activity of Aso volcano. J Volcanol Geotherm Res 56:319-338. https://doi.org/10.1016/03770273(93)90024-L

Terada A, Hashimoto T, Kagiyama T (2012) A water flow model of the active crater lake at Aso volcano, Japan: fluctuations of magmatic gas and groundwater fluxes from the underlying hydrothermal system. Bull Volcanol 74:641-655. https://doi.org/10.1007/s00445-011-0550-4

Tsutsui T, Sudo Y (2004) Seismic reflectors beneath the central cones of Aso Volcano, Kyushu, Japan. JVolcanol Geotherm Res 131:33-58. https://doi. org/10.1016/S0377-0273(03)00315-9

Usui Y (2015) 3-D inversion of magnetotelluric data using unstructured tetrahedral elements: applicability to data affected by topography. Geophys J Int 202:828-849. https://doi.org/10.1093/gji/ggv186

Usui Y et al (2017) Three-dimensional resistivity structure of Asama Volcano revealed by data-space magnetotelluric inversion using unstructured tetrahedral elements. Geophys J Int 208:1359-1372. https://doi.org/10.1093/ gji/ggw459

Wessel P, Smith WHF (1998) New, improved version of Generic Mapping Tools released. EOS Trans AGU 79(47):579. https://doi.org/10.1029/98EO00426

Yamamoto M et al (1999) Detection of a crack-like conduit beneath the active crater at Aso Volcano, Japan. Geophys Res Lett 26:3677-3680. https://doi. org/10.1029/1999GL005395

Yoshimura R et al (2018) Resistivity characterisation of Hakone volcano, Central Japan, by three-dimensional magnetotelluric inversion. Earth Planets Space 70:66. https://doi.org/10.1186/s40623-018-0848-y

\section{Submit your manuscript to a SpringerOpen ${ }^{\odot}$ journal and benefit from:}

- Convenient online submission

- Rigorous peer review

- Open access: articles freely available online

- High visibility within the field

- Retaining the copyright to your article

Submit your next manuscript at $\boldsymbol{\nabla}$ springeropen.com 